\title{
Determinants of growth monitoring and promotion service utilization among children 0-23 months of age in northern Ethiopia: unmatched case-control study
}

Samuel Dagne ${ }^{1 *}$, Jemal Aliyu ${ }^{1}$, Yonatan Menber ${ }^{1}$, Yosef Wassihun ${ }^{2}$, Pammla Petrucka $^{3}$ and Netsanet Fentahun ${ }^{1}$

\begin{abstract}
Background: One of the strategies to promote child health and reduce child mortality is growth monitoring and promotion services. But, there is limited information on determinants of Growth Monitoring and Promotion service utilization.

Objective: To identify determinants of growth monitoring and promotion (GMP) service utilization among children 0-23 months of age in Legambo district, South Wollo zone, Northern Ethiopia, 2020.

Methods: Community based un-matched case-control study was conducted on 363 (91 cases and 272 controls) study participants from March 15 to April 15, 2020. A multi-stage sampling technique was employed to select the study participants. Bivariable and multivariable logistic regressions were performed and an adjusted odds ratio with 95\% confidence intervals was estimated to identify determinants of GMP service utilization.

Results: A total of 358 mothers (89 cases and 269 controls) with $98.6 \%$ response rate were included in the study. The mean $( \pm \mathrm{SD})$ age of child was $11.66( \pm 6.29)$ months among controls and $15.02( \pm 6.06)$ months among cases. Good maternal knowledge $(A O R)=2.42 ; 95 \% \mathrm{Cl}: 1.23,4.75)$, favorable attitude ( $\mathrm{AOR}=2.45 ; 95 \% \mathrm{Cl} ; 1.20,4.98)$, counseling on GMP (AOR $=2.34 ; 95 \% \mathrm{Cl} ; 1.19,4.56)$, attending ante natal care services ( $\mathrm{AOR}=2.46 ; 95 \% \mathrm{Cl}: 1.18$, 5.16), index child age $12-17$ months ( $A O R=3.45 ; 95 \% \mathrm{Cl}: 1.26,9.41)$ and $18-23$ months ( $A O R=4.38 ; 95 \% \mathrm{Cl}: 1.53$, 12.49), and short distance to health facilities ( $\mathrm{AOR}=4.53 ; 95 \% \mathrm{Cl} ; 1.99,10.28$ ) were determinants of GMP service utilization.
\end{abstract}

Conclusion: Index child age, good knowledge, favorable attitude, attending antenatal care services, receiving nutritional counseling, and a short distance to health facility were determinants of GMP service utilization. Nutritional interventions should emphasize nutritional counseling and accessibility of growth monitoring and promotion services.

Keywords: Growth monitoring and promotion, Under two years' children, Legambo District, Northern Ethiopia

\footnotetext{
* Correspondence: samdagseg@gmail.com

'Department of Nutrition and Dietetics, School of Public Health, College of Medicine and Health Sciences, Bahir dar University, Bahir dar, Ethiopia

Full list of author information is available at the end of the article
}

(c) The Author(s). 2021 Open Access This article is licensed under a Creative Commons Attribution 4.0 International License, which permits use, sharing, adaptation, distribution and reproduction in any medium or format, as long as you give appropriate credit to the original author(s) and the source, provide a link to the Creative Commons licence, and indicate if changes were made. The images or other third party material in this article are included in the article's Creative Commons licence, unless indicated otherwise in a credit line to the material. If material is not included in the article's Creative Commons licence and your intended use is not permitted by statutory regulation or exceeds the permitted use, you will need to obtain permission directly from the copyright holder. To view a copy of this licence, visit http://creativecommons.org/licenses/by/4.0/ The Creative Commons Public Domain Dedication waiver (http://creativecommons.org/publicdomain/zero/1.0/) applies to the data made available in this article, unless otherwise stated in a credit line to the data. 


\section{Introduction}

Child malnutrition is one of the world's serious public health problems. Around $45 \%$ of deaths among children under 5 years of age are linked to undernutrition [1]. Worldwide, 151 million under-5 years of age children were stunted, 51 million were wasted, and 52 million were overweight [2]. Child malnutrition is also still a high public health problem in Ethiopia. According to the 2019 Ethiopian mini Demographic and Health Survey (EDHS) report, the prevalence of stunting was 37\%, underweight 21\%, and wasting $7 \%$ [3]. Similarly, the prevalence of stunting in the Amhara region was $41 \%$ which was the third-highest from the regions of the country [3].

Poor child growth and development in the early stages of life can increase the risk of infections, morbidity, and mortality together with decreased mental, cognitive and economic development [4-6]. The promotion of child growth and development is one of the health priorities to control child mortality and poverty reduction [7]. Even though Growth Monitoring and Promotion (GMP) is one of the prerequisites for good child health, several studies showed that there is a big difference between the purpose and the practice of GMP $[8,9]$. The high prevalence of malnutrition in many low and middle-income countries including Ethiopia supports this fact [3, 10, 11]. Participation in GMP remains relatively low in Ethiopia. Research findings from Southern Ethiopia showed that the coverage of GMP service utilization was $16.9 \%$ in the Mareka district [12], and 11\% in Butajira [13].

Previous studies reported that socio-demographic, maternal, and health professional-related factors influence GMP service utilization [12-18].

The National Nutritional Program (NNP) of Ethiopia considers GMP as one of the strategies for improving the nutritional status of the children and has been implementing at the community level through health extension programs. GMP is a prevention activity comprised of GM linked with a promotion that increases awareness about child growth; improves caring practices; increases demand other services, as needed; and serves as the core activity in an integrated child health and nutrition program [9]. Promoting and improving child health during the window of opportunity period starting from conception to a child's second birthday, is crucial for survival [19].

Even though the Ethiopian government has been implementing GMP services at a community level, the available data indicated that malnutrition is still high and participation in growth monitoring remains relatively low in the country. There is limited evidence on determinants of Growth Monitoring and Promotion service utilization in Ethiopia. This study aimed to identify determinants of GMP utilization among children less than 2 years in Legambo District, South Wollo zone, Northern Ethiopia. Therefore, identifying the determinants of low coverage of GMP service utilization helps nutrition program implementers to design evidencebased GMP interventions.

\section{Methods and materials \\ Study area and period}

The study was conducted from March 15 to April 15, 2020, in Legambo District, South Wollo zone, Northern Ethiopia. The district is found in the South Wollo zone Amhara region. it is situated on the beautiful highlands of south Wollo at an altitude of about $3000 \mathrm{~m}$ above sea level and is located $100 \mathrm{~km}$ to Dessie (the capital city of South Wollo zone), $430 \mathrm{~km}$ from Bahir Dar (the Capital city of the Amhara region) and $501 \mathrm{~km}$ far from Addis Ababa (the Capital city of Ethiopia). The district has 33 health Posts, 9 health centers, 1 hospital, 78 Health extension workers. The total population of the district was 281,974 with 147,160 males and 134,748 females while the total number of children with the age of o month to 23 months was 10,172 in the year 2017 which was projected from the Woreda Administration office [20].

\section{Study design}

A community-based unmatched case-control study design was employed.

\section{Eligibility criteria}

All mother-child pairs with $0-23$ months residing in the Legambo district during the study period were included in the study. Whereas, children with the age of 0 to 23 months suffering from chronic illnesses and those on treatment such as TB, HIV were excluded from the study.

\section{Sample size determination}

The sample size was calculated using Epi Info version 7.2.1.1 by considering the following assumptions: proportion of reach wealth status who utilized GMP service was 19.5\% among controls and 5\% among cases from the study conducted in Southern Ethiopia, 5\% type I error, $80 \%$ power, $1: 3$ cases to controls ratio, design effect of 1.5 and $10 \%$ non-response [12]. The final sample size was 363(91 cases and 272 controls).

\section{Sampling procedures}

A multi-stage sampling technique was used to select the study participants. Out of 34 kebeles in the district, 7 kebeles were selected using the lottery method. The list of mother-child pairs aged 0-23 months and their house numbers from each kebele were obtained from the health extension workers. House to house censuses was made to identify cases and controls and children aged 
$0-23$ months were identified and registered sequentially and had got identification number as case and control. And then, the total sample size was allocated proportionally to each kebele. Finally, both cases and controls were selected by a simple random sampling technique.

\section{Operational definitions}

Case: Participation of a child for GMP services at least once for 0 months, at least two times for 1-3 months, at least five times for 4-11 months, and at least four times per year for 12-23 months.

Control: a child who had not participated in GMP services at least once for 0 months, at least two times for $1-3$ months, at least five times for $4-11$ months, and at least four times per year for 12-23 months.

Good knowledge: is defined as scored above 7 from the total ten knowledge questions [13].

Poor knowledge: is defined as scored below 7 were considered as having poor knowledge [13].

Unfavorable attitude: is defined as a score of $<75 \%$.

A favorable attitude: is defined as a score of $\geq 75 \%$ [13].

\section{Data collection tools and procedures}

The data were collected using an interviewer-administered structured questionnaire. The questionnaire includes sociodemographic, economic, health care, behavioral factors, and maternal/caregiver's related characteristics and adapted from previous studies $[12,13,16,21,22]$ and collected by well trained and experienced two clinical nurses and three diploma midwives and three health officer supervisors.

ANC visit was assessed based on the minimum recommended visits (yes; for having four or more visits and no; for less than four visits). And, PNC was also assessed based on the minimum recommended visits (yes; for having at least one visit in the post-partum period and no; for not visits at all). The vaccination status of children was checked by observing the immunization card and if not available mothers /caregivers/ were asked to recall it. BCG vaccination was checked by observing a scar on right (also left) arm. The wealth index of households was determined using the Principal Component Analysis (PCA) by considering latrine, water source, household assets, livestock, and agricultural land adopted from EDHS 2016 [10]. The responses of all variables were classified into two scores. The highest score was coded as 1 and the lower score was given code 0 . Assumptions of PCA were checked to carry out the wealth index score. In PCA to determine the number of components that would retain, eigenvalue-one criterion was used and those variables having a commonality value of greater than 0.5 were used to produce factor scores. Lastly, the score for each household on the first principal component was retained to create the wealth score. Finally, tertials of the wealth score were created to categorize households as poor, medium, and rich.

Distance to health facility determined by the distance (time taken to reach the health facility from mothers' home to the nearest health facility). Distance to health facility was classified as less than $1 \mathrm{~h}$ and more than $1 \mathrm{~h}$ to reach the nearest health facility [23]. Knowledge of mothers towards GMP service utilization was assessed using ten knowledge questions. Each questions has two response (yes $=1$ or $0=$ no). The total score ranges from 0 to 10 . A score above 7 was categorized as good knowledge and below 7 was categorized as poor knowledge [13]. The attitude of the mother to GMP service was assessed by 12 attitude questions using Likert scale measures $(1=$ strongly disagree, $2=$ disagree, $3=$ neutral, $4=$ agree and $5=$ strongly agree). The total score ranges from 12 to 60 . A score of $\geq 75 \%$ was categorized as favorable attitude and a score of $<75 \%$ was categorized as unfavorable attitude [13].

\section{Data quality assurance}

The questionnaire was translated to the Amharic language and translated back to English to ensure consistency. The questionnaire was pre-tested in 5\% of the sampled population in non-selected kebeles before the actual data collection. Data collectors and supervisors were trained for 2 days. Test-retest reliability of the research instrument was established during pretesting. Test re-test reliability was established by examining the consistency of pre-test responses. On spot-checking and corrections were made for incomplete questionnaires by the supervisor. The overall data collection process was controlled by the principal investigator.

\section{Data processing and analysis}

The data were coded and entered and into Epi info version 7 and exported to SPSS version 23 for analysis. Descriptive statistics were computed and presented using tables, figures, and charts. Model goodness of fitness was assessed by using Hosmer and Lemeshow test. Multicolinearity between independent variables was checked. $\mathrm{Bi}$-variable logistic regression was executed and variables with $p<0.25$ were fitted to the final multivariable logistic regression to adjust for potential confounders. In the final model, variables with a $P$-value $<0.05$ and AOR of 95\% CI were considered to declare the statistical significance and the strength of association.

\section{Results}

Socio-economic characteristics of study participants

A total of 358 mothers (89 cases and 269 controls) with a $98.6 \%$ response rate were included in the study. The mean age of mothers was 27.28 with an SD of \pm 5.074 . The average family size was 4.4 with an SD of \pm 1.50 . About 
$55(61.8 \%)$ and $150(55.8 \%)$ of respondents were farmers among case and controls, respectively (Table 1).

\section{Growth monitoring and promotion service and child age} About 35 (39.3\%) and 74 (27.5\%) of children in the age group of 12-17 months age utilized GMP services in both cases and controls, respectively. Only 7(7.9\%) of children within the age group of $0-5$ months of age utilize GMP service among cases (Fig. 1).

\section{Maternal knowledge and attitude to GMP service}

The median knowledge and attitude scores among cases were $10(\mathrm{IQR}=10)$ and $51(\mathrm{IQR}=25)$, respectively. The median knowledge and attitude scores among controls were $14(\mathrm{IQR}=10)$ and $44 \quad(\mathrm{IQR}=29)$, respectively. Around $72(80.9 \%)$ of cases and $133(49.4 \%)$ of the controls group had good knowledge. Regarding the attitude; (83.1\% of cases and $48 \%$ of controls) had a favorable attitude. About 16 (18\%) of cases and 32\% of controls don't know when the growth monitoring service is started (Table 2).

\section{Health care service-related characteristics}

About $74(83.1 \%)$ mothers in the cases group (utilized) and $132(49.1 \%)$ mothers/caregivers in the controls group (Non- utilized) had 4 and above antenatal care (ANC) visits. The majority of mothers/caregivers in both cases group (67.4\%) and controls group (71\%) gave birth (for this baby) in health institutions. Only $70(78.7 \%)$ mothers in case groups and $123(45.7 \%)$ mothers in the control group were counseled on GMP (Table 3).

\section{Determinants of GMP service utilization}

In the Bivariable regression analysis, child age, paternal education, maternal education, antenatal care utilization, counseling on GMP service utilization, postnatal care

Table 1 Socio-economic characteristics of mothers/caregivers in Legambo district, South Wollo zone, Northern Ethiopia, 2020

\begin{tabular}{|c|c|c|c|}
\hline Variable & Category & Case: $n=89$ (\%) & Control: $n=269(\%)$ \\
\hline \multirow[t]{2}{*}{ Maternal age } & $15-30$ & $58(65.2)$ & $180(66.9)$ \\
\hline & $30-49$ & $31(34.8)$ & $89(33.1)$ \\
\hline \multirow[t]{2}{*}{ Marital status } & Married & $89(100)$ & $263(97.8)$ \\
\hline & Unmarried $^{a}$ & 0 & $6(2.2)$ \\
\hline \multirow[t]{4}{*}{ Maternal education } & Cannot read and write & $26(29.2)$ & $132(49.1)$ \\
\hline & Can read and write & $2(2.2)$ & $5(1.9)$ \\
\hline & Primary school & $31(34.8)$ & $94(34.9)$ \\
\hline & Secondary and above & $30(33.7)$ & $38(14.1)$ \\
\hline \multirow[t]{4}{*}{ Husband education } & Cannot read and write & $25(28.1)$ & $133(49.4)$ \\
\hline & Can read and write & $5(5.6)$ & $22(8.2)$ \\
\hline & Primary & $26(29.2)$ & $75(27.9)$ \\
\hline & Secondary and above & $33(37.1)$ & $39(14.5)$ \\
\hline \multirow[t]{4}{*}{ Occupation of mother } & Housewife & $22(24.7)$ & $99(36.8)$ \\
\hline & Farmer & $45(50.6)$ & $150(55.8)$ \\
\hline & Merchant & $11(12.4)$ & $12(4.5)$ \\
\hline & Employed & $11(12.3)$ & $8(3.0)$ \\
\hline \multirow[t]{4}{*}{ Husband occupation } & Farmer & $55(61.8)$ & $216(80.3)$ \\
\hline & Merchant & $8(9.0)$ & $28(10.4)$ \\
\hline & Employed & $26(29.2)$ & $17(6.3)$ \\
\hline & Others* & 0 & $8(3.0)$ \\
\hline \multirow[t]{3}{*}{ Wealth index } & High & $37(41.6)$ & $84(31.2)$ \\
\hline & Medium & $27(30.3)$ & $95(35.3)$ \\
\hline & Low & $25(28.1)$ & $90(33.5)$ \\
\hline \multirow[t]{2}{*}{ Family size } & $<4$ & $60(67.4)$ & $162(60.2)$ \\
\hline & $\geq 4$ & 29 (32.6) & $107(39.8)$ \\
\hline \multirow[t]{2}{*}{ Birth order } & 1 & $37(41.6)$ & $94(34.9)$ \\
\hline & $\geq 2$ & $52(58.4)$ & $175(65.1)$ \\
\hline
\end{tabular}




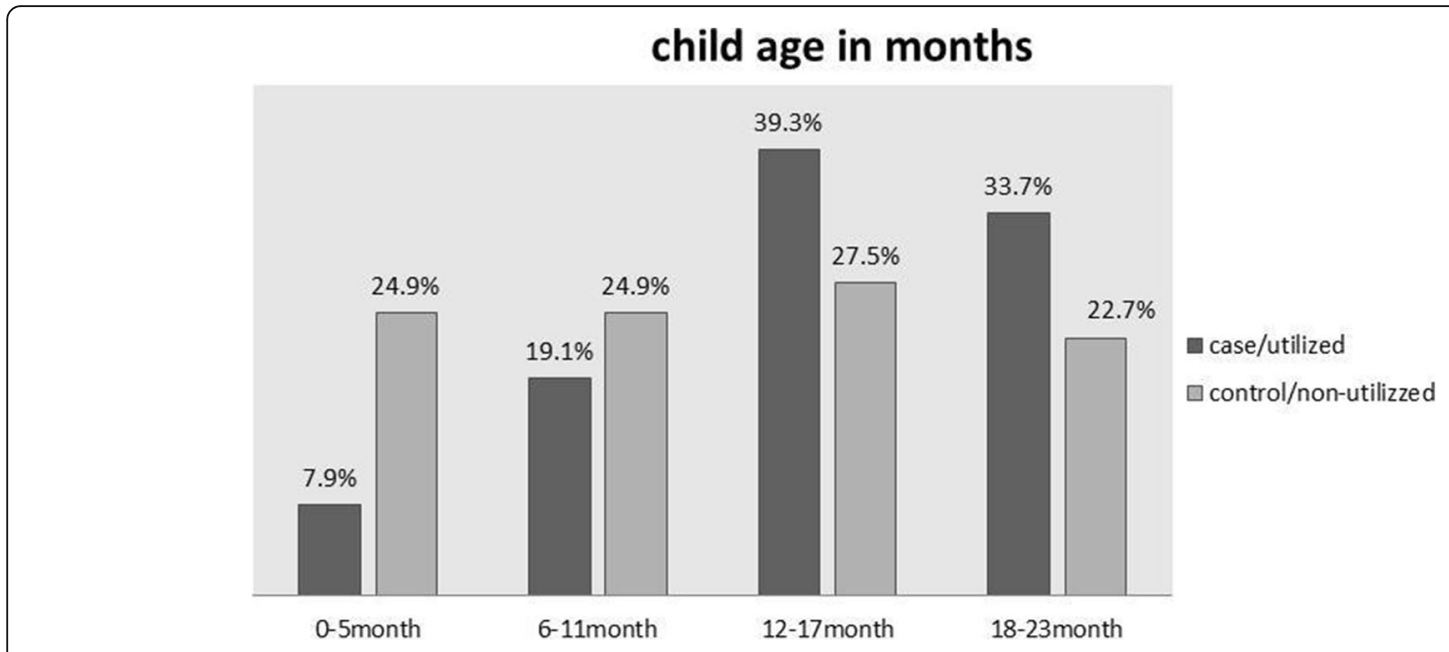

Fig. 1 Growth Monitoring and Promotion service and child age in Legambo district, South Wollo zone, Northern Ethiopia, 2020

Table 2 knowledge and attitude of mothers/caregivers towards GMP service utilization in Legambo district, South Wollo zone, Northern Ethiopia, 2020

\begin{tabular}{|c|c|c|c|}
\hline Variable & & Case: $n=89(\%)$ & Control: $n=269(\%)$ \\
\hline \multirow[t]{2}{*}{ Heard about GMP } & Yes & $87(97.8)$ & $194(72.1)$ \\
\hline & No & $2(2.1)$ & $75(20.9)$ \\
\hline \multirow[t]{2}{*}{ Know the age groups for GMP } & Yes & $77(86.5)$ & $193(75.4)$ \\
\hline & No & $12(3.4)$ & $76(21.2)$ \\
\hline \multirow[t]{2}{*}{ Know the starting time for GMP } & Yes & $73(82)$ & $183(68)$ \\
\hline & No & $16(18)$ & $86(32)$ \\
\hline \multirow[t]{2}{*}{ Know interval between GMP } & Yes & $82(92.1)$ & $175(65.1)$ \\
\hline & No & $7(7.9)$ & $94(34.9)$ \\
\hline \multirow[t]{2}{*}{ Know who to perform GMP } & Yes & $84(94.4)$ & $182(67.7)$ \\
\hline & No & $5(5.6)$ & $87(32.3)$ \\
\hline \multirow[t]{2}{*}{ Know place of GMP services } & Yes & $85(95.5)$ & $191(71)$ \\
\hline & No & $4(4.5)$ & $78(29)$ \\
\hline \multirow[t]{2}{*}{ GMP service has a benefit for the child } & Yes & $88(98.9)$ & $222(82.5)$ \\
\hline & No & $1(1.1)$ & $47(17.5)$ \\
\hline \multirow[t]{2}{*}{ Know when the growth chart is flattening } & Yes & $70(78.7)$ & $135(50.2)$ \\
\hline & No & $19(21.3)$ & $134(49.8)$ \\
\hline \multirow[t]{2}{*}{ Know when the growth chart is rising } & Yes & $70(78.7)$ & $134(49.8)$ \\
\hline & No & $19(21.3)$ & $135(50.2)$ \\
\hline \multirow[t]{2}{*}{ Know when the growth chart is falling } & Yes & $70(78.7)$ & $133(49.4)$ \\
\hline & No & $19(21.3)$ & $136(50.6)$ \\
\hline \multirow[t]{2}{*}{ Knowledge } & Good & $72(80.9)$ & $133(49.4)$ \\
\hline & Poor & $17(19.1)$ & $136(30.6)$ \\
\hline \multirow[t]{2}{*}{ Attitude } & Favorable & $74(83.1)$ & $129(48)$ \\
\hline & Unfavorable & $15(16.9)$ & $140(52)$ \\
\hline
\end{tabular}


Table 3 Health care service utilization-related characteristics of mothers/caregivers in Legambo district, South Wollo zone, Northern Ethiopia, 2020

\begin{tabular}{|c|c|c|c|}
\hline Variable & Categories & Case: $n=89(\%)$ & Control: $n=267(\%)$ \\
\hline \multirow[t]{2}{*}{ Place of delivery } & Home & $29(32.6)$ & $78(29)$ \\
\hline & Health institution & $60(67.4)$ & $191(71)$ \\
\hline \multirow[t]{2}{*}{ Immunization } & Fully immunized & $86(96.6)$ & $262(97.4)$ \\
\hline & Not immunized & $3(3.4)$ & $7(2.6)$ \\
\hline \multirow[t]{2}{*}{ ANC utilization } & Yes & $74(83.1)$ & $132(49.1)$ \\
\hline & No & $15(16.9)$ & $137(50.9)$ \\
\hline \multirow[t]{2}{*}{ PNC utilization } & Yes & $68(76.4)$ & $117(43.5)$ \\
\hline & No & $21(23.6)$ & $152(56.5)$ \\
\hline \multirow[t]{2}{*}{ Counseling on GMP } & Yes & $70(78.7)$ & $123(45.7)$ \\
\hline & No & $19(21.3)$ & $146(54.3)$ \\
\hline \multirow[t]{2}{*}{ Service quality } & Good & $51(57.3)$ & $127(47.2)$ \\
\hline & Poor & $38(42.7)$ & $142(52.8)$ \\
\hline \multirow[t]{2}{*}{ Distance to health facility } & $<1 \mathrm{~h}$ & 79 (88.8) & $154(57.2)$ \\
\hline & $\geq 1 \mathrm{~h}$ & $10(11.2)$ & $115(42.8)$ \\
\hline \multirow[t]{3}{*}{ Mode of delivery } & SVD & $85(95.5 \%)$ & 257 (95.5\%) \\
\hline & Instrumental & 0 & $5(2.6)$ \\
\hline & $\mathrm{C} /$ section & $4(4.5)$ & $7(4.5)$ \\
\hline \multirow[t]{2}{*}{ Counseled on nutrition } & Yes & $88(98.9)$ & $32(11.9)$ \\
\hline & No & $1(1.1)$ & $237(88.1)$ \\
\hline \multirow[t]{2}{*}{ Vitamin A supplementation } & Yes & $86(96.6)$ & $45(16.7)$ \\
\hline & No & $3(3.4)$ & $224(83.3)$ \\
\hline
\end{tabular}

utilization, knowledge, attitude, service quality, access to media, and distance to health facility were associated with the GMP at $p$-value $<0.25$. Finally, variables with a p-value $<0.25$ were transferred to multivariable logistic regression and child age, knowledge, attitude, counseling on GMP, ANC service utilization and distance to health facility were independent predictors of GMP service utilization at $p$-value $<0.05$. Mothers/caregivers who had good knowledge were 2.4 times more likely to utilize GMP service compared to mothers/caregivers who had poor Knowledge $(\mathrm{AOR})=2.42$; 95\% CI: 1.23, 4.75). Mothers/caregivers who had received counseling on GMP service were 2.3 times more likely to utilize GMP service compared to mothers/caregivers who had not received counseling ( $\mathrm{AOR}=2.34,95 \% \mathrm{CI}$ : 1.19, 4.56). Mothers/caregivers who reached nearby the health facility less than one hour were 4.5 times more likely to utilize GMP service as compared to mothers/caregivers who reached greater than one hour $(\mathrm{AOR}=4.53 ; 95 \%$ CI: $1.99,10.28)$.

Mothers/caregivers who had utilized ANC services were 2.46 times more likely to utilize GMP services as compared to mothers/caregivers who had not utilized ANC services $(A O R=2.46 ; 95 \%$ CI: 1.18, 5.16). Mothers $/$ caregivers/ who had favorable attitudes were 2.45 times more likely to utilize GMP services as compared to unfavorable attitudes $(\mathrm{AOR}=2.45 ; 95 \% \mathrm{CI}: 1.20,4.98)$. Mothers who have children age group between 12 and 17 months were 3 times and 18-23 months age groups were 4 times more likely to utilize GMP services as compared to who have Children with $0-5$ age groups $(\mathrm{AOR}=3.45 ; 95 \% \mathrm{CI}: 1.26,9.41)$ and $(\mathrm{AOR}=4.38 ; 95 \%$ CI: $1.53,12.49)$, respectively (Table 4 ).

\section{Discussions}

This study aimed to identify determinants of Growth monitoring and promotion service utilization using an unmatched case-control study among less than two years children and the study will generate information for the Ministry of Health and other organizations working in the child survival programs to design interventions to improve the activities of GMP.

The study pointed out that determinants of growth monitoring and promotion service utilization were index child age, maternal knowledge, maternal Attitude, utilization of ANC services, getting counseling about GMP, and distance to reach the nearest health facility.

Mother who had adequate knowledge of growth monitoring was more likely utilizes GMP than mother who had inadequate knowledge. A similar finding was 
Table 4 Predictors of GMP services utilization among children 0-23 months of age in Legambo district, South Wollo zone, Northern Ethiopia, 2020

\begin{tabular}{|c|c|c|c|c|c|}
\hline \multirow[t]{2}{*}{$\mathbf{N}$} & \multirow[t]{2}{*}{ Categories } & \multirow[t]{2}{*}{ Cases } & \multirow[t]{2}{*}{ Controls } & \multicolumn{2}{|c|}{$95 \%$ confidence interval } \\
\hline & & & & COR & AOR \\
\hline \multirow[t]{4}{*}{ Maternal education } & Illiterate & $26(29.2 \%)$ & $132(49.1 \%)$ & 1 & 1 \\
\hline & Read and write & $2(2.2 \%)$ & $5(1.9 \%)$ & $2.03(0.37-11.04)$ & $1.32(0.19-9.17)$ \\
\hline & Primary & $31(34.8 \%)$ & $94(34.9 \%)$ & $1.67(0.93-3.00)$ & $1.29(0.52-3.22)$ \\
\hline & Secondary and above & $30(33.7 \%)$ & $38(14.1 \%)$ & $4.01(2.12-7.58)$ & $1.96(0.68-5.69)$ \\
\hline \multirow[t]{4}{*}{ Partner education } & Illiterate & $25(28.1 \%)$ & $133(49.4 \%)$ & 1 & 1 \\
\hline & Read and write & $5(5.6 \%)$ & $22(8.2 \%)$ & $1.21(0.42-3.49)$ & $0.89(0.23-3.50)$ \\
\hline & Primary & $26(29.2 \%)$ & $75(27.9 \%)$ & $1.84(0.99-3.42)$ & $1.25(0.49-3.19)$ \\
\hline & Secondary and above & $33(37.1 \%)$ & $39(14.5 \%)$ & $4.5(2.39-8.46)$ & $1.87(0.68-5.13)$ \\
\hline \multirow[t]{4}{*}{ Child age in months } & $0-5$ & $7(7.9 \%)$ & 67 (24.9\%) & 1 & 1 \\
\hline & $6-11$ & $17(19.1 \%)$ & $67(24.9 \%)$ & $2.43(0.95-6.24)$ & 2.67-(0.91-7.85) \\
\hline & $12-17$ & 35 (39.3\%) & $74(27.5 \%)$ & $4.53(1.89-10.87)^{*}$ & $3.45(1.26-9.41)^{*}$ \\
\hline & $18-23$ & $30(33.7 \%)$ & $61(22.7 \%)$ & $4.70(1.93-11.49)^{* *}$ & $4.38(1.53-12.49)^{* *}$ \\
\hline \multirow[t]{2}{*}{ Maternal knowledge } & Good & $72(80.9 \%)$ & $133(49.4 \%)$ & $4.33(2.42-7.73)^{*}$ & $2.42(1.23-4.75)^{*}$ \\
\hline & Poor & $17(19.1 \%)$ & $136(30.6 \%)$ & 1 & 1 \\
\hline \multirow[t]{2}{*}{ Maternal attitude } & Favorable & $74(83.1 \%)$ & $129(48.0 \%)$ & $5.35(2.92-9.79)^{*}$ & $2.45(1.20-4.98)^{*}$ \\
\hline & Unfavorable & 15 (16.9\%) & $140(52.0 \%)$ & 1 & 1 \\
\hline \multirow[t]{2}{*}{ Counseling on GMP } & Yes & $70(78.7 \%)$ & $123(45.7 \%)$ & $4.37(2.49-7.66)^{*}$ & $2.34(1.19-4.56)^{*}$ \\
\hline & No & $19(21.3 \%)$ & $146(54.3 \%)$ & 1 & 1 \\
\hline \multirow[t]{2}{*}{ Access to media } & Yes & $52(58.4 \%)$ & $114(42.4 \%)$ & $1.91(1.18-3.11)^{*}$ & $0.92(0.48-1.77)$ \\
\hline & No & $37(41.6)$ & $155(57.6 \%)$ & & \\
\hline \multirow[t]{2}{*}{ Distance to health facility } & $<1 \mathrm{~h}$ & $79(88.8 \%)$ & $154(57.2 \%)$ & $5.89(2.93-11.89)^{* *}$ & $4.53(1.99-10.28)^{* *}$ \\
\hline & $>1 \mathrm{~h}$ & $10(11.2 \%)$ & $115(42.8 \%)$ & 1 & 1 \\
\hline \multirow[t]{2}{*}{ ANC service utilization } & Yes & $74(83.1 \%)$ & $132(49.1 \%)$ & $5.12(2.79-9.37)^{*}$ & $2.46(1.18-5.16)^{*}$ \\
\hline & No & $15(16.9 \%)$ & $137(50.9 \%)$ & 1 & 1 \\
\hline \multirow[t]{2}{*}{ PNC service utilization } & Yes & $68(76.4 \%)$ & $117(43.5 \%)$ & $4.20(2.44-7.26)^{*}$ & $1.89(0.95-3.62)$ \\
\hline & No & $21(23.6 \%)$ & $152(56.5 \%)$ & 1 & 1 \\
\hline
\end{tabular}

"P-value $<0.05 ;{ }^{* *} P$-value $<0.001$, COR Crude odds ratio, AOR Adjusted odds ratio

reported from the study done in Areka town, Butajira, Kenya, and Ghana [13, 15, 21, 22]. This can be explained by the mother with adequate knowledge may able to understand the information displayed on the growth chart and that motivates to utilize GMP session.

In this study, a child in the age group of 6-11 months and 12-23 months were found that more likely to utilize GMP services as compared to infants in the age group of 0-5 months. This finding is similar to a study done in Southern Ethiopia Mareka district [12] and Butajira [21]. This could be explained in Ethiopian culture mothers perceived that taking their child to the GMP session will expose their child to the "evil eye". Exposing children in front of people until they started walking is not accepted by the mothers [24]. These attitudes cause some mothers to be reluctant to attend the GMP session. Therefore, the GMP uptake may be improved in the first year of life considering the local cultural beliefs [25].

This study showed that mothers/caregivers who had favorable attitudes were more likely to utilize than those who had unfavorable attitudes. This finding was supported by a study on Areka town, southern Ethiopia [13]. The reason for this might be a good attitude of mother's leads to happy to bring their child to the GM visits and this helps to utilize GMP session and for unfavorable attitude, one qualitative study conducted Loko Abaya District, Southern Ethiopia [24] showed that Mothers mentioned that they understood GMP as being used only for unhealthy (especially wasted) children. If their children are healthy and well-fed, they did not want to attend the GMP program.

According to this study mothers who utilized ANC services were more utilize GMP services than those who 
had not ANC service utilization. The possible justification for this may be during Antenatal care nutritional counseling is given and most of the mothers understand the service that was got from the health institution and after delivery, the mothers will be happy to attend the GMP session. This result is different from a study done in the Mareka district [12] showed that there is no significant association between the utilization of ANC services and GMP service utilization. This difference is may be due to study design; the previous study was used cross-sectional while this study was used case-control study design and time difference, at this time the coverage of ANC is increased.

This study identified that mothers/caregivers who received counseling about growth monitoring and promotion were more likely to utilize GMP services than those who did not receive counseling. This study is in line with a study in Kenya [15] which showed mothers/caregivers who received nutrition advice alongside GM services were more likely to participate in continued. The reason for this may be counseling has a greater impact on motivating mothers to attend GMP sessions.

In this study, mothers who traveled less than an hour to get to the nearest health facility from their home were more likely to utilize GMP services for those who travel more than one hour to get to the nearest health facility. This finding is similar to study in Southern Ethiopian, Mareka district [12] and also supported by the study in Kenya [15] showed that distance from respondent's home to the facility $5 \mathrm{~km}$; return journey were significantly associated with continued GM and similarly in Ghana [22] stated that distance between caregivers home and the child welfare clinic is a determining factor in child welfare clinic (CWC) attendance. The possible justification for this may be due to long distances to the health facilities may be a hindrance to the mothers to continue with growth monitoring especially if the children are looking well because of the competing roles. Socio-economic variables included in this study (marital status, occupation of mother, family size of the household, and wealth index) were not significantly associated with GMP service utilization. This might be due to the similar nature or living standard of mother was included in the study. Majority of mothers were farmers, married and lived in similar setting. As a limitation, there might be a recall bias while assessing the growth chart knowledge of the mothers, utilization of ANC service, and PNC services.

In this study, both maternal and partner education at the secondary level and above are significant in the unadjusted model. Despite the lack of statistical significance at the adjusted model, the maternal and paternal literacy /education seemed to show a trend in uptake of services with higher levels of education.

\section{Conclusion}

Child age, good knowledge towards growth monitoring, favorable attitude towards growth monitoring and promotion, utilization of ANC services, counseling towards growth monitoring and promotion, and time to reach the nearest health facility within one hour were determinants of GMP service utilization. Nutritional interventions should emphasize nutritional counseling, utilization of ANC service, and accessibility of growth monitoring and promotion service to improve growth monitoring and promotion service utilization and reduce malnutrition in Ethiopia. It is also recommended that GMP services should be culturally sensitive.

\section{Abbreviations \\ ANC: Ante Natal Care; AOR: Adjusted Odd Ratio; CSA: Central Statistics Agency; Cl: Confidence Interval; DSS: Demographic Surveillance System; EDHS: Ethiopian Demographic Health Survey; GM: Growth Monitoring; GMP: Growth Monitoring and Promotion; PNC: Post Natal Care; SD: Standard Deviation}

\section{Supplementary Information}

The online version contains supplementary material available at https://doi. org/10.1186/s40795-021-00470-y.

Additional file 1. Questionnaire_English version.

\section{Acknowledgments}

We would like to thanks Bahir Dar University, data collectors, supervisors, and study participants.

\section{Authors' contributions}

JA, SD, and NF assisted in the conception of the study, developed the proposal, involved in the method development, analysis, interpretation of the findings, and the development of a manuscript. YW and YM were involved in the method development, interpretation of the findings, and development of a manuscript. PP edited and provided guidance for content to enhance the quality of the manuscript. All the authors read, revised, and approved the final manuscript.

\section{Authors information}

SD, JA, YM, and NF: Department of Nutrition and Dietetics, School of Public Health, College of Medicine and Health Sciences, Bahir dar University, P.O. Box 79, Bahir Dar, Ethiopia.

YW: Department of Health Promotion and Behavioral Sciences, School of Public Health, College of Medicine and Health Sciences, Bahir dar University, P.O.Box, 79, Bahir Dar, Ethiopia. PP: University of Saskatchewan, Saskatoon, SK, Canada

\section{Funding}

The authors declare that there is no funding source.

\section{Availability of data and materials}

The datasets generated and/or analysed during the current study are not publicly available due to limitations of ethical approval involving the patient data and anonymity but are available from the corresponding author on reasonable request.

\section{Declarations}

Computing interests

The authors declare that they have no competing interests. 


\section{Ethics approval and consent to participate}

Ethical clearance was obtained from the Institutional Review Board of College of Medicine and Health Sciences, Bahir Dar University. An official support letter was obtained from the Woreda administration. Written consent was obtained from the mothers/caregivers after informing all the purposes, benefits, and risks of the stud. All methods were performed by the relevant guidelines and regulations. This research is original and not considered in another journal for publication.

\section{Consent for publication}

Not applicable.

\section{Author details}

'Department of Nutrition and Dietetics, School of Public Health, College of Medicine and Health Sciences, Bahir dar University, Bahir dar, Ethiopia. ${ }^{2}$ Department of Health Promotion and Behavioral Sciences, School of Public Health, College of Medicine and Health Sciences, Bahir dar University, Bahir dar, Ethiopia. ${ }^{3}$ University of Saskatchewan, Saskatoon, SK, Canada.

Received: 14 November 2020 Accepted: 15 September 2021

Published online: 08 November 2021

\section{References}

1. Organization, W.H. Malnutrition Key Facts. World Health Organization; 2018 p. 1-7. https://www.who.int/news-room/fact-sheets/detail/malnutrition.

2. UNICEF, Levels, and trends in child malnutrition. 2018, social sciences.

3. Institute, E.P.H. and ICF. Ethiopia mini demographic and health survey 2019: key indicators. Rockville: EPHI and ICF; 2019.

4. Black RE, Allen LH, Bhutta ZA, Caulfield LE, de Onis M, Ezzati M, et al. Maternal and child undernutrition: global and regional exposures and health consequences. Lancet. 2008;371(9608):243-60. https://doi.org/10.101 6/S0140-6736(07)61690-0.

5. Communication, U.D.O. Tracking progress on child and maternal nutrition: a survival and development priority. Unicef; 2009. https://www.unicef.fr/sites/ default/files/userfiles/Tracking_Progress_on_Child_and_Maternal_Nutrition_ EN_110309.pdf.

6. Organization, W.H. Stunted growth and development, Context, Causes, and Consequences. World Health Organization; 2017. https://www.who.int/ nutrition/events/2013_ChildhoodStunting_colloquium_140ct_Conceptua IFramework_colour.pdf.

7. Liu Q, Long Q, Garner P. Growth monitoring and promotion (GMP) for children in low and middle-income countries. Cochrane Database Syst Rev. 2017;2017(1). https://doi.org/10.1002/14651858.CD010102.pub2.

8. Ashworth A, Shrimpton R, Jamil K. Growth monitoring and promotion: a review of the evidence of impact. Matern Child Nutr. 2008;4(s1):86-117. https://doi.org/10.1111/j.1740-8709.2007.00125.x.

9. Bilal SM, et al. Practices and challenges of growth monitoring and promotion in Ethiopia: a qualitative study. J Health Popul Nutr. 2014; 32(3):441.

10. Ethiopia, Ethiopia Demographic and Health Survey, 2016. 2012: ICF International, central Statistical Agency, July 2017.

11. Fanzo, J., et al., 2018 Global Nutrition Report: Shining a light to spur action on nutrition 2018

12. Feleke FW, Adole AA, Bezabih AM. Utilization of growth monitoring and promotion services and associated factors among under two years of age children in southern Ethiopia. PLoS One. 2017:12(5):e0177502. https://doi. org/10.1371/journal.pone.0177502.

13. Daniel B, Tesfaye N, Mekonin E, Kassa A, Mensur K, Zerihun E, et al. Knowledge and attitude on growth monitoring and its associated factors among mothers/guardians of children less than two years in Areka town, southern Ethiopia, 2017. J Nutr Disorders Ther. 2017;7(216):2161-0509. 1000216. https://doi.org/10.4172/2161-0509.1000216.

14. Melkamu AW, Bitew BD, Muhammad EA, Hunegnaw MT. Prevalence of growth monitoring practice and its associated factors at public health facilities of North Gondar zone, Northwest Ethiopia: an institution-based mixed study. BMC Pediatr. 2019;19(1):144. https://doi.org/10.1186/s12887-01 9-1489-4.

15. Nyabuti Jl. Factors associated with the continuation of growth monitoring among children 10 to 59 months old in Nyamira County, Kenya. Nairobi: Unpublished Masters dissertation, Kenyatta University; 2015.
16. Baraki T, Gebru AA, Belay D. Knowledge attitude and practice of health extension workers towards growth monitoring and promotion program in Tigray region. Ethiopia Eur J Biomed Pharm Sci. 2018;3(4):55-64.

17. Saaka M. Relationship between mothers' nutritional knowledge in childcare practices and the growth of children living in impoverished rural communities. J Health Popul Nutr. 2014;32(2):237.

18. Sahanggamu PD, Purnomosari L, Dillon D. Information exposure and growth monitoring favor child nutrition in rural Indonesia. Asia Pac J Clin Nutr. 2017;26(2):313-6. https://doi.org/10.6133/apjcn.012016.09.

19. Shekar $\mathrm{M}$, et al. Investing in nutrition: the Foundation for Development-an investment framework to reach the global nutrition targets. Washington, DC: World Bank, results for development, Bill and Melinda Gates Foundation, CIFF, Thousand days; 2016

20. office, L.W.a., The district population projection. 2017.

21. Desalegne H, S.S., and Haile. D, Assessment of knowledge and utilization of growth monitoring and promotion for under two children in Butajira. 2017.

22. Debuo T, et al. Caregivers knowledge, attitude, and practices on child growth monitoring and promotion activities in Lawra District, upper west region of Ghana. Sci J Public Health. 2017;5(1):20-30. https://doi.org/10.1164 8/j.sjph.20170501.13.

23. Delamater PL, Messina JP, Shortridge AM, Grady SC. Measuring geographic access to health care: raster and network-based methods. Int J Health Geogr. 2012;11(1):15. https://doi.org/10.1186/1476-072X-11-15.

24. Tekle M, Tariku B, Alagaw A, Zerihun E, Bekele HW. Exploring reasons for low attendance of mothers to growth monitoring and promotion program at Loka Abaya District, southern Ethiopia: exploratory qualitative study. J Nutr Metabol. 2019;2019:1-7. https://doi.org/10.1155/2019/3510649.

25. Resnicow K, Baranowski T, Ahluwalia JS, Braithwaite RL. Cultural sensitivity in public health: defined and demystified. Ethn Dis. 1999;9(1):10-21.

\section{Publisher's Note}

Springer Nature remains neutral with regard to jurisdictional claims in published maps and institutional affiliations.
Ready to submit your research? Choose BMC and benefit from:

- fast, convenient online submission

- thorough peer review by experienced researchers in your field

- rapid publication on acceptance

- support for research data, including large and complex data types

- gold Open Access which fosters wider collaboration and increased citations

- maximum visibility for your research: over $100 \mathrm{M}$ website views per year

At $\mathrm{BMC}$, research is always in progress.

Learn more biomedcentral.com/submissions 